Tunneling Microscopy.

Qing Ma, Massachusetts Institute of Technology, (Paper K1.5) Effect of Grain Boundary Structure on Grain Boundary Diffusivities in the Au/Ag System.

John B. Deppe, University of California, (Paper L2.6) Network Dynamics and Lattice Dynamics Studies of Vibrational Modes in Lithium Doped Borate Glasses.

Sossina M. Haile, Massachusetts Institute of Technology, (Paper L10.6) Syntheses, Structure, and Ionic Conductivity of $\mathrm{K}_{3} \mathrm{NdSi}_{6} \mathrm{O}_{15}$.

Cathy Lane, University of Pennsylvania, (Paper L2.4) Molecular Dynamics Simulations of Ion Transport in Beta"-Alumina.

Laurence D. Howe, University of Birmingham, (Paper M1.7) Molecular Flow in a Model Pore System.

Gilles Chanvillard, University de Sherbrooke, (Paper O4.4) MicroMechanical Modeling of the Pull-Out Behaviour of Corrugated Steel Fibres From Cementitious Matrices.

Robert J. Finch, University of New Mexico, (Paper P6.2) Phase Relations of the Uranyl Oxide Hydrates and their Significance to the Disposal of Spent Fuel.

Joel P. Nic, Michigan Technological University, (Paper Q10.21) Alloying of $\mathrm{A1}_{3} \mathrm{~T}_{\mathbf{1}}$ with $\mathrm{Mn}$ and $\mathrm{Cr}$ to Form Cubic $\mathrm{L1}_{2}$ Phases.

Joseph D. Rigney, Case Western Reserve, (Paper Q14.2) Loading Rate Effects on Ductile-Phase Toughening in In-situ Niobium Silicide-Niobium Composites.

Philip G. Kaatz, Carnegie Mellon University, (Paper R1-1.3) Third-Order Nonlinear Optical Properties of Polysilane Films.

Michael F. Roberts, University of Rochester, (Paper R2-1.5) Effects of Complexation on the Glass Transition Temperature of Polymers.

Emmanuel D. Dimotakis, Michigan State University, (Paper S4.9) New Route to Layered Double Hydroxides (LDHs) Interlayered by Organic Anions: Precursors to Pillared Microporous Derivatives.

Thomas M. Breunig, Georgia Institute of Technology, (Paper U3.7) Impact of Xray Tomographic Microscopy on Deformation Studies of a SiC/Al MMC.

Michael J. Dougherty, University of Massachusetts, (Paper V2.5) In Vivo Synthesis of Chain Folded Polypeptides Using Natural Consensus $\beta$-Hairpin Residues.

Jian-Ping Zheng, State University of New York at Buffalo, (Paper Y5.6) Optical Properties and Carrier Dynamics of Semiconductor Microcrystals.

\title{
Inaugural Winners Announced in MRS Medals Competition
}

A physicist and a chemist, both from Northwestern University and both active in the study of novel types of materials, will be the first two scientists to receive the MRS Medal. Arthur J. Freeman of Northwestern's Department of Physics and Duward F. Shriver of the Materials Research Center and Department of Chemistry will receive the awards during special ceremonies at the 1990 MRS Fall Meeting in Boston.

The MRS Medal is awarded in recognition of a specific outstanding research achievement having major impact on the progress of any of the numerous fields which together comprise materials research.

Freeman will be recognized for pioneering achievements in laying the foundations of the newly developing field of monolayer magnetism and artifically layered magnetic materials. "This is an area that has recently captured the imagination of a diversity of materials scientists," says John Baglin (IBM Almaden Research), chair of the Medals Selection Committee. "It is also a concept that promises to revolutionize our view of the nature of magnetic phenomena at an atomic scale."

Shriver will receive the MRS Medal in recognition of his seminal work in the synthesis, characterization, understanding and application of polymer-based solid electrolyte materials. "The impact of Professor Shriver's work is impressive," says Baglin, "both intellectually and in emerging applications such as new kinds of commercial batteries. His work, creatively and dynamically developing the science of a novel set of materials having designed properties, has opened new and significant vistas for current applications and future basic materials studies."

Each Medalist will present a special invited paper dealing with his award research as part of the Symposium $X$ series, Frontiers of Materials Research, at the 1990 MRS Fall Meeting.

\section{Arthur J. Freeman}

Professor Freeman's innovative work has taken the form of specific computational predictions concerning the fundamental physical properties of manmade magnetic structures, the nature of the magnetic order, the magnitude of the magnetic moments, the hyperfine fields, the electric field gradients, the surface magnetic anisotropy and surface relaxation effects. His

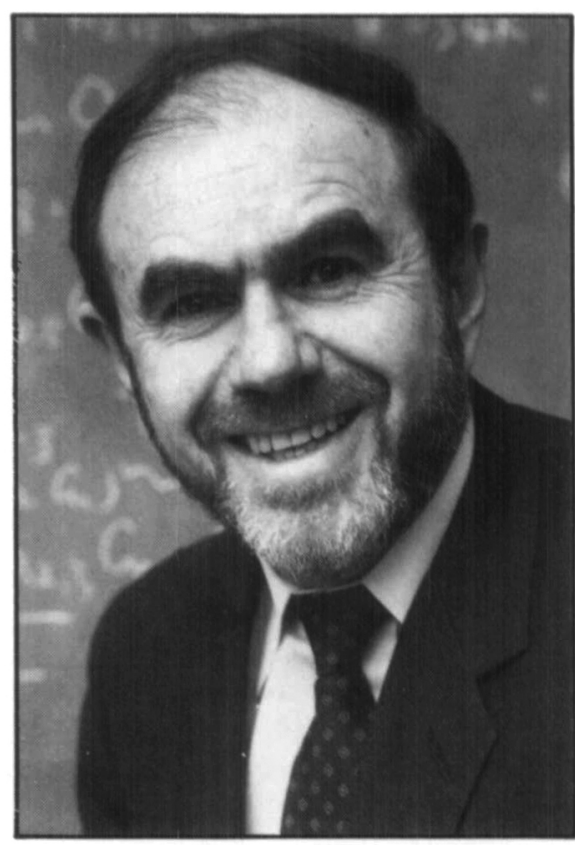

Arthur J. Freeman

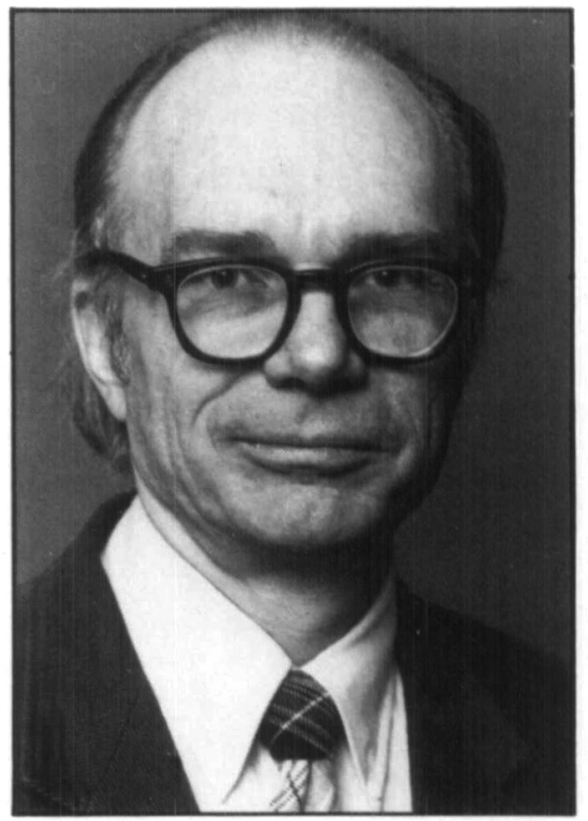

Duward F. Shriver

dramatic predictions of "giant" moments were presented when it was still fashionable to consider surfaces to be magnetically intrinsically dead. Related experimental and theoretical work on low-dimensional magnetic materials has become a major 
new field of materials research, intensely pursued and holding fascinating possibilities for future applications and fundamental studies.

Freeman's work exemplifies his leadership in the emerging area of "computational" materials science, centering on the concept that a supercomputer can be viewed as the equivalent of a growth chamber or molecular-beam epitaxy machine, to synthesize and design new materials, and to gain insights into their behavior and properties. His major role in introducing a class of new and fascinating materials complements his numerous other distinguished contributions to the development of materials research.

\section{Duward F. Shriver}

While polymer electrolytes were first studied in Europe, Professor Shriver's laboratory produced the first comprehensive synthetic characterization of themleading to completely new insights into their structure and the mechanisms of ionic transport within them. After successfully developing a continuum elastomeric network interpretation of the mobility mechanism in simple polymer/salt complexes based on polyethylene oxide, Shriver turned his attention to the preparation of new polymer solid electrolytes with tailored properties. A key achievement was his work on the synthesis and characterization of phosphazine-based polymer electrolytes with oligo ether side chains. The combination of the phosphazine backbone (to yield low glass transition temperature and mobility) with oligo ether side chains (to provide complexation to drive the system thermodynamically, towards the elastomeric conductor) was a triumph of imagination and creative solid-state materials.

Shriver's most recent investigation - of polymer-mixed conductors in which both electronic charge and ionic charge are transferred-presents one of the most challenging problems in understanding how charge transport occurs in disordered systems with mixed conductivity.

\section{MRS Members Choose 1991 Officers, Councillors}

MRS members cast their ballots this past September to elect three officers and five councillors. Newly elected to serve the Materials Research Society beginning January 1, 1991 are:

\section{First Vice President}

(President-Elect)

G. Slade Cargill III

Senior Manager, Physical Sciences

Department

IBM T.J. Watson Research Center

Yorktown Heights, New York

\section{Second Vice President}

S. Thomas Picraux

Manager, Surface, Interface, and Ion

Beam Research Department

Sandia National Laboratories

Albuquerque, New Mexico

\section{Treasurer}

\section{Charles B. Duke}

Senior Research Fellow

Xerox Research Laboratories

Webster, New York
Councillors

John C. Bravman

Assistant Professor, Department of

Materials Science and Engineering

Stanford University

Stanford, California

\author{
Gregory C. Farrington \\ Dean, School of Engineering and \\ Applied Science \\ University of Pennsylvania \\ Philadelphia, Pennsylvania
}

Julia M. Phillips

Supervisor, Thin Film Research Group

AT\&T Bell Laboratories

Murray Hill, New Jersey

\section{Rustum Roy}

Director, Technology and Society Program

Pennsylvania State University

University Park, Pennsylvania
Carl V. Thompson

Associate Professor, Department of Materials Science and Engineering

Massachusetts Institute of Technology Cambridge, Massachusetts

James B. Roberto, associate director of the Solid State Division at Oak Ridge National Laboratory, who was elected first vice president last year, will serve as president of the Materials Research Society in 1991. Carol M. Jantzen, a ceramist in the Glass Technology Group at the Westinghouse Savannah River Co., will continue to serve her two-year term as treasurer through 1991.

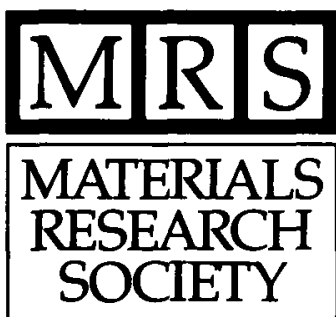

